\title{
Endovascular coil embolization of segmental arteries prevents paraplegia after subsequent thoracoabdominal aneurysm repair: An experimental model
}

\author{
Sarah Geisbüsch, MD, ${ }^{\mathrm{a}}$ Angelina Stefanovic, ${ }^{\mathrm{a}}$ Jacob S. Koruth, MD, ${ }^{\mathrm{b}}$ Hung-Mo Lin, ScD, \\ Susan Morgello, MD, ${ }^{\mathrm{d}}$ Donald J. Weisz, MD, ${ }^{\mathrm{e}}$ Randall B. Griepp, MD, ${ }^{\mathrm{a}}$ and Gabriele Di Luozzo, $\mathrm{MD}^{\mathrm{a}}$
}

Objectives: To test a strategy for minimizing ischemic spinal cord injury after extensive thoracoabdominal aneurysm (TAAA) repair, we occluded a small number of segmental arteries (SAs) endovascularly 1 week before simulated aneurysm repair in an experimental model.

\begin{abstract}
Methods: Thirty juvenile Yorkshire pigs $(25.2 \pm 1.7 \mathrm{~kg})$ were randomized into 3 groups. All SAs, both intercostal and lumbar, were killed by a combination of surgical ligation of the lumbar SAs and occlusion of intercostal SAs with thoracic endovascular stent grafting. Seven to 10 days before this simulated TAAA replacement, SAs in the lower thoracic/upper lumbar region were occluded using embolization coils: $1.5 \pm 0.5 \mathrm{SAs}$ in group 1 (T13/L1), and $4.5 \pm 0.5 \mathrm{SAs}$ in group 2 (T11-L3). No SAs were coiled in the controls. Hind limb function was evaluated blindly from daily videotapes using a modified Tarlov score $(0=$ paraplegia, $9=$ full recovery). After death, each segment of spinal cord was graded histologically using the 9-point Kleinman score $(0=$ normal, $8=$ complete necrosis $)$.
\end{abstract}

Results: Hind limb function remained normal after coil embolization. After simulated TAAA repair, paraplegia occurred in 6 of 10 control pigs, but in only 2 of 10 pigs in group 1; no pigs in group 2 had a spinal cord injury. Tarlov scores were significantly better in group 2 (control vs group $1, P=.06$; control vs group $2, P=.0002$; group 1 vs group $2, P=.05$ ). A dramatic reduction in histologic damage, most prominently in the coiled region, was seen when SAs were embolized before simulated TAAA repair.

Conclusions: Endovascular coiling of 2 to 4 SAs prevented paraplegia in an experimental model of extensive hybrid TAAA repair, and helped protect the spinal cord from ischemic histopathologic injury. A clinical trial in a selected patient population at high risk for postoperative spinal cord injury may be appropriate. (J Thorac Cardiovasc Surg 2014;147:220-7)

Thoracoabdominal aneurysms (TAAAs), if untreated, carry a high risk of a lethal outcome, but elective repair to prevent death from rupture is associated with a formidable risk of complications: paraplegia is probably the most devastating. It is known that intraoperative and perioperative management-including hypothermia, cerebrospinal fluid drainage, blood pressure control, and monitoring of motor-evoked potentials - can lead to a dramatic reduction in the incidence of immediate postoperative paraplegia,

From the Department of Cardiothoracic Surgery, ${ }^{\mathrm{a}}$ Department of Cardiology, Department of Health Evidence and Policy, ${ }^{\mathrm{c}}$ Department of Neuropathology, ${ }^{\mathrm{d}}$ Department of Neurology, ${ }^{\mathrm{e}}$ Mount Sinai Medical Center, New York, NY.

This study was supported by grant R01 HL 045636 from the National Heart, Lung and Blood Institute.

Disclosures: Susan Morgello reports lecture fees from Health Clear Strategies. All other authors have nothing to disclose with regard to commercial support.

Read at the 93rd Annual Meeting of The American Association for Thoracic Surgery, Minneapolis, Minnesota, May 4-8, 2013.

Received for publication May 3, 2013; accepted for publication Sept 4, 2013; available ahead of print Nov 11, 2013

Address for reprints: Sarah Geisbüsch, MD, Department of Cardiothoracic Surgery, Mount Sinai Medical Center, One Gustave L. Levy Place, PO Box 1028, New York, NY 10029 (E-mail: sarah.geisbuesch@ hotmail.com).

$0022-5223 / \$ 36.00$

Copyright $(\odot) 2014$ by The American Association for Thoracic Surgery

http://dx.doi.org/10.1016/j.jtcvs.2013.09.022 with a shift to delayed paraplegia. The extent of surgical sacrifice or endograft-induced occlusion of intercostal, lumbar, and other vessels, such as the subclavian and hypogastric arteries, which support spinal cord perfusion, is the most important factor predisposing to spinal cord injury.

A series of experimental studies in our laboratory has enabled us to better understand the pathophysiology and anatomy of spinal cord perfusion after segmental artery (SA) sacrifice, and to develop strategies to protect spinal cord integrity. Blood flow studies using microspheres have shown that spinal cord blood flow, as a percentage of mean arterial pressure (MAP), decreases after sacrifice of all SAs in an experimental model, and takes 72 to 120 hours to recover to preoperative levels. ${ }^{1}$ During this vulnerable interval, it is especially important to maintain strict control of blood pressure and cerebrospinal fluid drainage.

Anatomic studies using acrylic resin, ${ }^{2}$ and a viscous radiopaque fluid to image the vasculature, ${ }^{3}$ show a dense collateral network within the spinal canal and paraspinous muscles with many interconnections. Studies after extensive SA ligation made it clear that vessels nourishing the spinal cord increase in size to compensate for 

Abbreviations and Acronyms
MAP = mean arterial pressure
SA $=$ segmental artery
TAAA $=$ thoracoabdominal aortic aneurysm

diminished input postoperatively, and also that small new vessels develop over time. An increase in vessel diameter and density can be seen already at 24 hours after extensive SA sacrifice, and this progresses for 5 days postoperatively, which is when full recovery of blood flow and pressure to baseline levels usually is seen. These observations reinforce the idea that the spinal cord blood supply consists of many interconnecting vessels rather than depending on a single vessel-the artery of Adamkiewicz-as commonly believed. The existence of this extensive vascular network, which can compensate for the loss of specific inputs, is what we have called the "collateral network concept."

When studies simulating TAAA repair were performed in our pig model in 2 stages 1 week apart, a dramatic improvement in functional outcome was noted. All animals who underwent a 2-stage sacrifice of all SAs fully recovered their hind limb function, whereas $40 \%$ of animals in whom all SAs were sacrificed in a single procedure were paraplegic. ${ }^{4}$ Clinical observations of open surgical experience added to the credibility of this experiment. Patients who underwent TAAA repair in 2 stages suffered paraplegia at much lower rates than patients with comparable surgeries performed in a single stage.

Although reports of hybrid repair of TAAAs cast some doubt on the efficacy of a staged strategy in preventing paraplegia in clinical practice, ${ }^{6-11}$ our experience in an experimental model simulating the clinical hybrid approach showed excellent results. There was no paraplegia in staged pigs despite a $40 \%$ to $50 \%$ incidence of spinal cord injury in single-stage controls. ${ }^{12}$ Our explanation for this remarkable result is that the first procedure in a staged approach stimulates a process, most likely mediated by ischemia, that results in a cascade of angiogenic and arteriogenic mechanisms. In the current study, we aimed to find a less invasive stimulus that would allow us to induce this angiogenic response before undertaking extensive aneurysm resection in a single stage. We wanted to stimulate the protective response provoked by the first stage of a 2-stage procedure for eventual use in patients with aneurysms not suitable for conventional 2 -stage repair.

\section{METHODS}

All animals received humane care in compliance with the guidelines of the "Principles of Laboratory Animal Care" formulated by the National Society for Medical Research and the "Guide for the Care and Use of Laboratory Animals" published by the National Institute of Health (publication no. 88-23, revised 1996). The study was approved by the Mount Sinai Institutional Research Committee.

Thirty juvenile Yorkshire pigs (weight, $25.2 \pm 1.7 \mathrm{~kg}$ ) were randomized into 3 groups. All groups underwent simulated TAAA repair: sacrifice of all SAs, with surgical ligation of the lumbar SAs followed immediately by endovascular stenting of the descending thoracic aorta. Group 1 underwent endovascular occlusion of $1.5 \pm 0.5 \mathrm{SAs}$ at 7 to 10 days before simulated TAAA repair using embolization coils (Cook stainless steel embolization coils; Cook Medical, Bloomington, Ind); in group 2, $4.5 \pm 0.5$ SAs were coiled before SA sacrifice. No SAs were coiled in the controls (group 0).

Pigs were videotaped daily until postoperative day 7 . The paraplegic pigs were killed on postoperative day 3 .

\section{Coiling Procedure}

Premedication with intramuscular xylazine $(2.0 \mathrm{mg} / \mathrm{kg})$, ketamine $(15 \mathrm{mg} / \mathrm{kg})$, and atropine $(0.03 \mathrm{mg} / \mathrm{kg})$, was followed by endotracheal intubation and mechanical ventilation with a fraction of inspired oxygen of 0.5 , and a minute volume adequate for maintenance of a normal $\mathrm{PCO}_{2}$ level $(35-40 \mathrm{~mm} \mathrm{Hg}$ ). Anesthesia was maintained with $1 \%$ to $2 \%$ isoflurane. An $8 \mathrm{~F}$ introducer was placed in the femoral artery and heparin was administered. Coils were delivered through a standard angiographic catheter using a straight guidewire. In the pig, segmental vessels frequently arose as a single bifurcating trunk, therefore 1 or 2 coils were required to occlude both branches. Angiograms determined the correct catheter position before and after embolization, and confirmed occlusion of each segmental vessel after administration of protamine (Figure 1). Blood pressure was monitored continuously. Intramuscular buprenorphine $(0.03 \mathrm{mg} / \mathrm{kg}$ both preoperatively and postoperatively) was used for analgesia.

\section{Stenting and Ligation}

After premedication and intubation, anesthesia was induced via the bolus intravenous administration of propofol $(1 \mathrm{mg} / \mathrm{kg})$ and fentanyl $(50 \mu \mathrm{g} / \mathrm{kg})$, and maintained with infusions of ketamine $(15 \mathrm{mg} / \mathrm{kg} / \mathrm{h})$, propofol $(7 \mathrm{mg} / \mathrm{kg} / \mathrm{h})$, and fentanyl $(5 \mu \mathrm{g} / \mathrm{kg} / \mathrm{h})$. The pig was cooled to $32^{\circ} \mathrm{C}$ using a cooling blanket.

Through a left flank incision, the abdominal aorta was mobilized from the diaphragm to the bifurcation. After identification, each SA from Th12/13 to L5 was ligated surgically in a cephalocaudal sequence, and the incision was closed.

A $12 \mathrm{~F}$ introducer sheath then was placed in the femoral artery. An angiogram confirmed correct stent position. Two thoracic stents $(14 \times 14.5 \mathrm{~cm}, 12 \times 12 / 12 \times 10 \mathrm{~cm})$ were placed, with oversizing of $15 \%$ to $25 \%$ to prevent migration. Correct stent positioning-inclusion of all SAs but with patency of the subclavian artery and the celiac trunk-was verified with fluoroscopy.

After removal of the sheath, the animal was weaned from anesthesia and rewarmed. Ventilatory support was decreased gradually until the animal was breathing spontaneously. Blood pressure was monitored constantly until the animal awoke. Regular analgesic medication was administered postoperatively. Intramuscular banamine $(1-2 \mathrm{mg} / \mathrm{kg}$ twice daily for 3 days); buprenorphine as previously noted, and a fentanyl patch $(50 \mu \mathrm{g} /$ h) for the first 72 hours.

\section{Stent Grafts}

Stents were donated by W. L. Gore \& Associates, Inc (Flagstaff, Ariz). To fit the thoracic aorta of juvenile Yorkshire pigs, the Gore Excluder AAA Endoprosthesis was chosen (catalogue numbers PXC141400, PXC121000, and PXC121200)

\section{Behavioral Evaluation}

Pigs were videotaped 5 hours postoperatively, and daily after both coiling and the ligation procedure. All videotapes were scored by a neurophysiologist blinded to the experimental groups. Hind limb function 

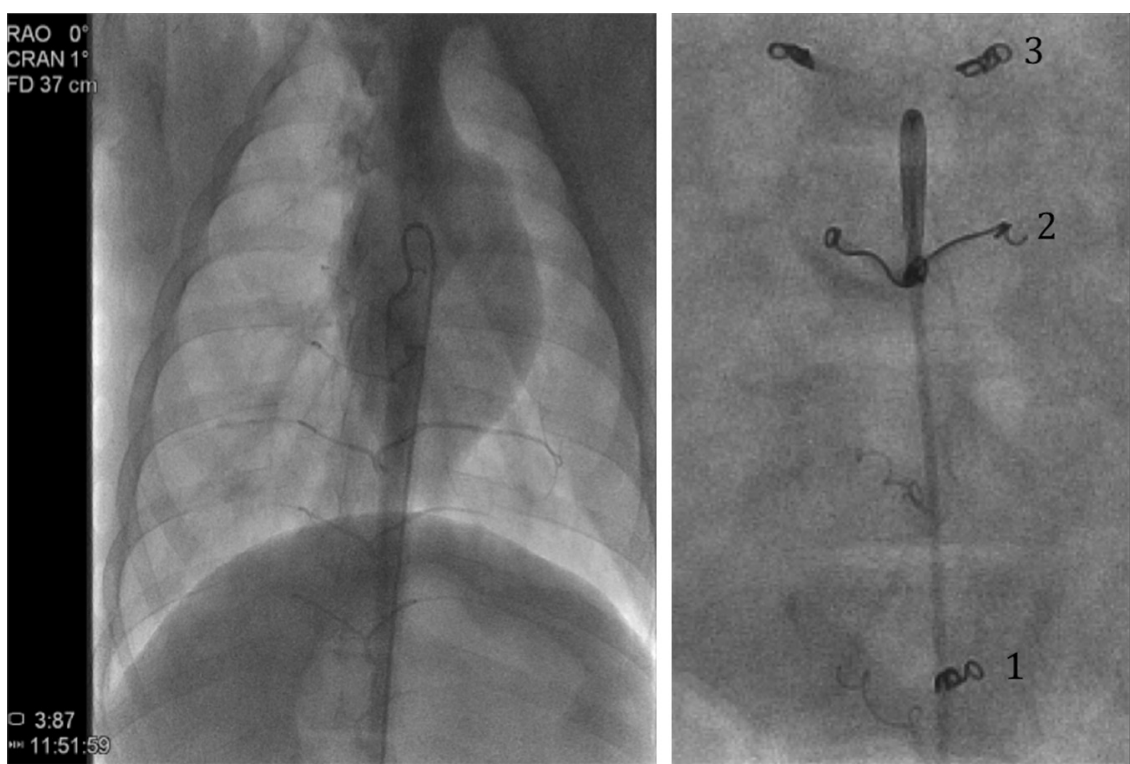

FIGURE 1. Coiling procedure. The number of segmental arteries was verified in each pig at the beginning of the coiling procedure (left). Pushable coils were placed either in the main trunk of the segmental arteries (right, l) or, if needed, one coil was placed in each branch to embolize the vessels (right, 2: part of both coils remains in the main trunk of the segmental artery; 3: one coil is placed in each branch of the segmental artery) using a hockey stick-shaped catheter and a standard guidewire. Angiograms were performed before embolization to determine the correct catheter position, and again after embolization. The occlusion of each segmental vessel was verified angiographically after administration of protamine.

was evaluated using a modified Tarlov scale, previously described in detail, in which 0 indicated no voluntary movements and 9 indicated full recovery.

\section{Histology}

The spinal cord was excised surgically after death, fixed in $40 \%$ formalin for 6 days, sectioned transverse to the craniocaudal axis, and fixed in formalin for another 3 days. Each sample included one spinal nerve root from $\mathrm{C} 1$ to $\mathrm{S} 1$. Sections $5-\mu \mathrm{m}$ thick were stained with hematoxylin-eosin. All samples were scored blindly by an experienced neuropathologist grading the histopathologic damage on a 9-point scale that we have called the Kleinman score, also previously described in detail. ${ }^{4}$ The scale allows assessment of both gray and white matter: 1 indicates necrosis of single (motor) neurons only; and 8 denotes complete necrosis of the entire section.

The Kleinman scores of all sections were added to produce a histopathologic injury score. Both the total injury score and the number of injured levels were analyzed and compared between groups for the entire spinal cord and for various regions within it. Coverage of all SAs in the stented area and the occlusion of coiled and ligated SAs was verified (Th4-L5) during necropsy.

\section{Statistical Analysis}

Data were entered into an Excel spreadsheet (Microsoft Corp, Redmond, Wash) and transferred to an SAS file (SAS Institute, Inc, Cary, NC) for data description and analysis. Descriptive data are presented as percentages, medians with ranges, or means \pm standard deviations. For group comparison, the chi-squared test or the Fisher exact test was used for categoric variables, and the 2-sample $t$ test, analysis of variance, or Wilcoxon test was used for continuous variables, as appropriate. For repeatedly measured Tarlov and Kleinman data, a mixed model, with groups and times (or regions) as the fixed effects and pigs as the random effects, was used to compare the differences among the 3 groups. Least squares means and standard error were reported.

\section{RESULTS}

The mean weight of the pigs (controls, $24.9 \pm 2 \mathrm{~kg}$; group $1,25.1 \pm 1.8 \mathrm{~kg}$; group $2,25.5 \pm 1.2 \mathrm{~kg}$ ), MAP during the coiling procedure (group 1, $78 \pm 11 \mathrm{~mm} \mathrm{Hg}$; group 2, 77 $\pm 15 \mathrm{~mm} \mathrm{Hg})$, intraoperative temperature $\left(32^{\circ} \mathrm{C}\right.$ in all 3 groups), average duration of the ligation procedure (controls, $156 \pm 54 \mathrm{~min}$; group 1, $138 \pm 33 \mathrm{~min}$; group 2, $138 \pm 39 \mathrm{~min}$ ), and the average number of SAs (controls, $14.1 \pm 0.6$; group $1,14.4 \pm 0.8$; group $2,14.2 \pm 0.9$ ) were not significantly different. The postoperative MAP was higher in group $1(94 \pm 8 \mathrm{~mm} \mathrm{Hg}$ ) and in group 2 (93 \pm $11 \mathrm{~mm} \mathrm{Hg}$ ) than in control pigs $(82 \pm 11 \mathrm{~mm} \mathrm{Hg})$, and was significant for control versus group $1(P=.02)$. An average of $1.5 \pm 0.5 \mathrm{SAs}$ were coiled in group 1 , and 4.5 \pm 0.5 SAs were coiled in group 2 .

\section{Functional Outcome}

Animals with a modified Tarlov score less than 6 at the end of the protocol were considered to have sustained significant spinal cord injury. Paraplegia occurred in $60 \%$ of pigs that underwent surgery in the control group (6 of 10) and in 2 of 10 pigs in group $1(20 \%)$. None of the pigs in group 2 was paraparetic or paraplegic $(P=.01)$. One pig in group 1 was paraparetic, but hind limb function improved within 7 days.

Pairwise comparison showed a highly significant difference in functional outcome between the control group and group 2. The average Tarlov score was $3.4 \pm 0.9$ in controls, $5.8 \pm 0.8$ in group 1 , and $7.5 \pm 0.2$ in group 2 ( 0 vs 2 , $P<.001 ; 1$ vs $2, P=.05$; and 0 vs $1, P=.06$ ) (Figure 2 ).

The number of SAs coiled was correlated significantly and positively with Tarlov scores $(P<.0001)$. All pigs in which 2 or more SAs were coiled recovered hind limb function. 

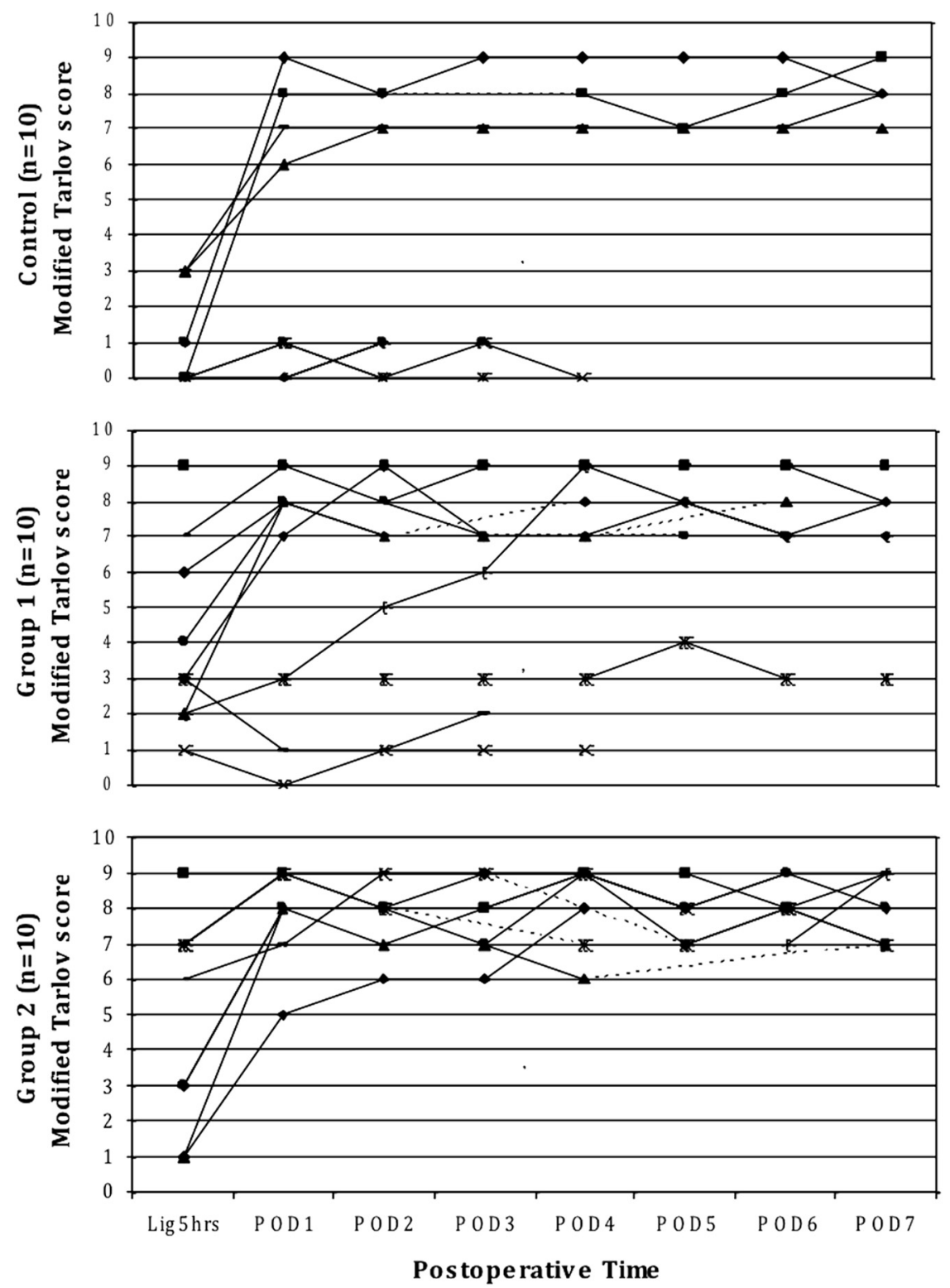

FIGURE 2. Behavioral evaluation. Hind limb function was assessed using a modified Tarlov score, with zero indicating no movement, and 9 indicating fully normal function, as detailed in the text. The recovery of hind limb function is shown in each pig over a period of 7 days after complete SA occlusion. Six animals in the control group remained paraplegic: 2 in group 1 and none in group $2(P<.0001$ for group 0 vs group $2 ; P=.05$ for group 1 vs group 2 ; and $P=.06$ for group 0 vs group 1). Paraplegic pigs were killed after 3 days.

\section{Histology}

As seen in Table 1 , the average histopathologic injury score was $33.2 \pm 25.3$ in group $0,20.1 \pm 26.1$ in group 1 , and $4.0 \pm 5.0$ in group 2 , and was significantly different for group 0 versus group $2(P=.004)$. The analysis of different regions of the spinal cord also showed differences in histopathologic injury score between group 0 and group 2 for all 3 regions, and for group 2 versus both other groups for the coiled region. The number of injured levels showed similar results except that the average number of injured levels in the region T5 to T10 was not significantly different between groups (group 0, $2.9 \pm 2.6$; group 1, $1.6 \pm 2$; group $2,1 \pm 1.1)$

In the coiled region, an average of $3.3 \pm 2.3$ levels in control pigs and $2.4 \pm 2.5$ in group 1 showed necrosis, whereas only $0.2 \pm 0.4$ levels in group 2 were injured (group 0 vs group $2, P=.001$ ). The cervical and lower lumbar regions showed little damage, $1.1 \pm 1.6$ levels in controls, $0.3 \pm$ 0.7 levels in group 1, and 0 levels in group 2 (group 0 vs group $2, P=.03$ ). Overall, an average of $7.3 \pm 4.4$ sections showed necrosis in the controls: $4.3 \pm 4.5$ in group 1 and 1.2 \pm 1.4 in group 2 (group 2 vs group $0, P=.007$ ) (Figure 3 ). 
TABLE 1. Histopathology

\begin{tabular}{|c|c|c|c|c|c|c|c|c|}
\hline \multicolumn{5}{|c|}{ Histopathologic injury score } & \multicolumn{4}{|c|}{$P$ values } \\
\hline Region & Group & $\mathbf{N}$ & Mean & Standard deviation & Overall & 0 vs 1 & 0 vs 2 & 1 vs 2 \\
\hline \multirow[t]{3}{*}{ Entire cord } & 0 & 10 & 33.2 & 25.4 & .028 & .224 & .004 & .157 \\
\hline & 1 & 10 & 20.1 & 26.2 & & & & \\
\hline & 2 & 10 & 4.0 & 5.0 & & & & \\
\hline \multirow[t]{3}{*}{ T5-T10 } & 0 & 10 & 14.6 & 13.2 & .175 & .239 & .071 & .665 \\
\hline & 1 & 10 & 7.6 & 10.5 & & & & \\
\hline & 2 & 10 & 3.5 & 4.7 & & & & \\
\hline \multirow[t]{3}{*}{ T11-L3 } & 0 & 10 & 16.8 & 15.0 & .007 & .338 & .001 & .025 \\
\hline & 1 & 10 & 11.7 & 15.4 & & & & \\
\hline & 2 & 10 & 0.5 & 1.1 & & & & \\
\hline \multirow[t]{3}{*}{$\mathrm{C} 1-\mathrm{T} 4+\mathrm{L} 4-\mathrm{S} 1$} & 0 & 10 & 1.8 & 2.2 & .035 & .252 & .033 & .474 \\
\hline & 1 & 10 & 0.8 & 1.7 & & & & \\
\hline & 2 & 10 & 0 & 0 & & & & \\
\hline
\end{tabular}

Average histopathologic injury score for group 0 (control), group 1 (coiling of 1-2 SA), and group 2 (coiling of 4-5 SAs) for the entire spinal cord (C1-S1), and analyzed by region. Bold numbers indicate significant differences.

The Kleinman score was significantly different for paraplegic and nonparaplegic pigs (total score and number of injured levels in all regions, $P<.001$; injury score and number of injured levels in cervical plus lower lumbar regions, $P=.009$ and .011 , respectively). The correlation between paraplegia and histologic injury was high: a histopathologic injury score greater than 40 has a coefficient of 1 . The presence of 8 or 9 injured levels likewise was highly correlated with paraplegia (coefficient, 0.989).

The number of SAs coiled was correlated significantly and negatively with histologic spinal cord damage (overall neurologic injury score, $P=.0008$; number of injured levels, $P=.0004$; coiled region T11-L3, both $P<.0001$ ). Animals in which 4 or more SAs were coiled showed significantly less spinal cord damage than those without coiling.

\section{Comment}

The anatomy and pathophysiology of the spinal cord vasculature have been described in detail in earlier reports. ${ }^{2,3,13,14}$ Based on the observation that diminished input to spinal cord blood flow owing to sacrifice of a certain number of SAs leads to dilatation of existing vessels as well as development of new, small vessels in compensation, we sought a strategy to stimulate this process before extensive aortic aneurysm repair. We hypothesized that this then would allow TAAA resection to be performed in a single stage with minimal risk of spinal cord injury. In our experimental model, we embolized SAs 1 week before TAAA repair, simulated by surgical ligation of abdominal SAs (T11/12-L5) immediately followed by stent grafting of the thoracic aorta (T4-T11/12).

All animals in which 2 or more SAs were embolized recovered without functional impairment. The number of coiled SAs correlated significantly with the histologic damage seen in the spinal cord, and with functional outcome. The group in which 4 or more SAs were coiled had significantly less spinal cord damage after the subsequent extensive SA sacrifice than was seen in both other groups.

Interestingly, the reduction of histologic spinal cord damage was seen most prominently in the area in which SAs had been coiled (T11-L3) in both groups. Thus, one could propose that coiling of SAs induces mechanisms

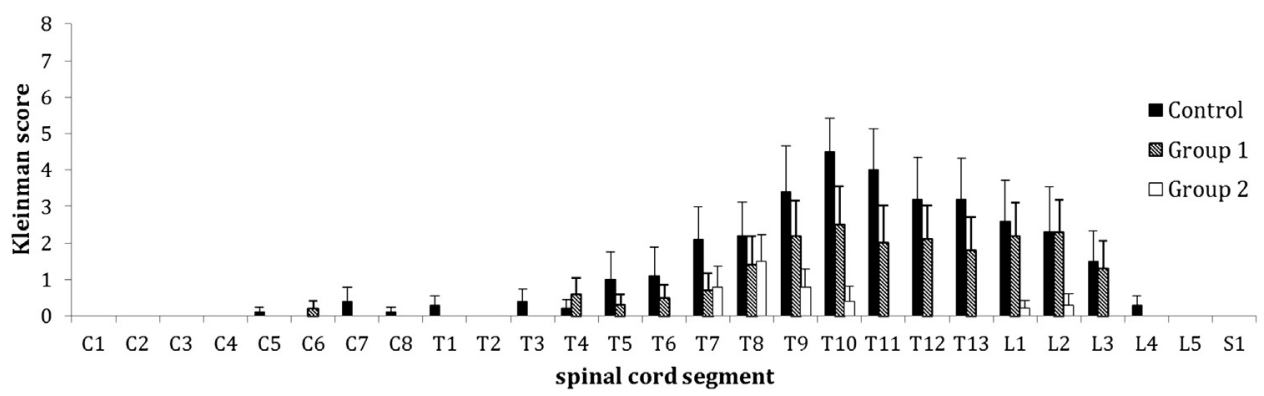

FIGURE 3. Histologic outcome. The average Kleinman score is shown per group for each individual level of the spinal cord: higher scores indicate greater histopathologic damage, as detailed in the text. Spinal cord damage was most prominent in the T9-T13 region. Almost no necrosis was seen in the coiled region (T11-L3) for group 2. 
that protect the spinal cord from damage, most likely by providing an ischemic stimulus provoking subsequent angiogenesis. But coiling itself does not seem to cause any persistent ischemia, which causes histologic cell damage or leads to loss of function. Surprisingly, in our experiment, coiling of only 2 SAs was enough to dramatically reduce the damage after simulated TAAA repair, with little or no risk of causing any damage as a result of the preliminary procedure.

Our experience from experimental as well as clinical studies suggests that paraplegia is almost never seen if TAAA repair is performed in 2 stages. This improved outcome was observed both in staged open procedures and staged hybrid procedures in an animal model. ${ }^{4,5,12}$ In these experimental studies, an interval of 7 days between procedures was sufficient to improve outcome dramatically: from $40 \%$ to $50 \%$ paraplegia to $0 \%$. A retrospective analysis of 90 patients undergoing surgery at Mount Sinai Medical Center who underwent open TAAA repair showed that the paraplegia rate likewise was significantly lower in patients who underwent surgery in 2 stages, with a median interval of 5 years between procedures: 0 of 35 patients had spinal cord injury compared with $15 \%$ undergoing extensive single-stage procedures ( 8 of 55 patients developed paraplegia). The difference in outcome was seen despite the fact that the number of SAs that were sacrificed was significantly higher in the 2 -stage group (median, 12 vs $14 ; P<.0001$ ). ${ }^{5}$ In their extensive experience, Coselli et $\mathrm{al}^{15}$ also noted a lower incidence of paraplegia when extensive TAAA repair was performed in 2 stages.

The staging of extensive TAAA repair already has been implemented in clinical practice where feasible and appropriate. The results, however, remain controversial. A recent single-center study identified the staged hybrid approach to be superior to concurrent repair of extensive TAAAs,${ }^{11}$ which supports the clinical data of Patel et al ${ }^{16}$ from 2012. In the study by Hughes et al, ${ }^{11}$ of 47 patients who underwent hybrid repair (33 in 1 procedure, and 14 in 2 stages), only 2 patients suffered paraplegia, and both had undergone simultaneous repair. The paraplegia rate was $4.3 \%$. Wong et $\mathrm{al}^{17}$ reported a large series of 509 patients, of whom 161 had open extensive TAAA repair (Crawford extent II): permanent paraplegia was seen in $3.7 \%$. However, various other studies have proposed that patients undergoing endovascular TAA aneurysm repair after previous or concomitant AAA repair are at higher risk for spinal cord injury. ${ }^{10,18}$ We think that this is most likely owing to sacrifice of other important vessels such as the hypogastric or the subclavian arteries.

In recent studies, postoperative hypotensive episodes, even after discharge, often were reported as the reason for delayed paraplegia, reflecting the tenuous spinal cord blood supply present early after extensive TAAA repair even under optimal circumstances. In our experiment, although postoperative pressures were slightly higher in the groups that had undergone coiling, this was only significant in comparing the controls with group 1, and thus cannot explain the dramatic results of preliminary coiling in group 2 . Why the postoperative pressures were slightly lower in the control group is unknown because the animals were treated identically. It may be that the ischemic injury occurring in the control group resulted in some loss of vasomotor tone, a mild form of spinal shock. Nevertheless, scrupulous maintenance of high normal blood pressures after extensive SA sacrifice remains an important safeguard of spinal cord integrity.

Although we think that the strategy of coiling SAs has high translational potential, there were limitations to the study. All animals in our study were healthy and all SAs were patent before embolization. Patients who are eligible for elective procedures and therefore would allow a scheduled coiling procedure before aneurysm repair oftentimes suffer from degenerative aneurysms. This may lead to difficulties and complications from atheroembolism of plaques and thrombus when performing an endovascular procedure. In addition, the majority of such patients may have some SAs already occluded by mural thrombus. ${ }^{19}$ Thus, preprocedural evaluation of SA patency by angiography, computed tomography, or magnetic resonance imaging may be helpful in determining when coiling may be of benefit, and in planning the procedure. Such imaging studies, including selective intercostal angiography, already have been used by Williams et $\mathrm{al}^{19}$ in their attempt to identify the so-called artery of Adamkiewicz-the artery believed to be critical to spinal cord blood supply.

Even if successful, our strategy of provoking remodeling of the collateral network would be applicable only to a very specific subset of patients who require extensive TAAA repair. Patients at high risk of rupture, for example, would not be eligible for this kind of preprocedural intervention. However, this minimally invasive approach would be very attractive for elective patients with high comorbidity whose extensive aneurysms are not suitable for conventional staged repair.

Further investigation needs to be performed with regard to the pathophysiology of the changes that occur after coiling SAs. Once we understand the mechanisms, we ideally would identify a way clinically to monitor whether a stimulus adequate to produce angiogenesis and arteriogenesis has taken place after coiling, and thus when it is safe to proceed with extensive aneurysm repair.

\section{CONCLUSIONS}

These results indicate that preliminary endovascular coiling of a few SAs can prevent paraplegia in an experimental model of extensive TAAA repair. A mild ischemic stimulus induced by the coiling procedure 
probably activates mechanisms within the collateral network to enhance spinal cord blood flow, and thereby minimizes ischemic cord injury after subsequent extensive SA sacrifice. After coiling, extensive singlestage TAAA repairs in patients who are unable to undergo conventional 2 -stage procedures could be performed at a much lower risk for spinal cord injury. A clinical trial in a population at high risk for postoperative paraplegia may be appropriate.

\section{References}

1. Etz CD, Homann TM, Luehr M, Kari FA, Weisz DJ, Kleinman G, et al Spinal cord blood flow and ischemic injury after experimental sacrifice of thoracic and abdominal segmental arteries. Eur J Cardiothorac Surg. 2008;33: 1030-8.

2. Etz CD, Kari FA, Mueller CS, Silovitz D, Brenner RM, Lin HM, et al. The collateral network concept: a reassessment of the anatomy of spinal cord perfusion. J Thorac Cardiovasc Surg. 2011;141:1020-8.

3. Geisbusch S, Schray D, Bischoff MS, Lin HM, Griepp RB, Di Luozzo G. Imaging of vascular remodeling after simulated thoracoabdominal aneurysm repair. J Thorac Cardiovasc Surg. 2012;144:1471-8.

4. Zoli S, Etz CD, Roder F, Brenner RM, Bodian CA, Kleinman G, et al. Experimental two-stage simulated repair of extensive thoracoabdominal aneurysms reduces paraplegia risk. Ann Thorac Surg. 2010;90:722-9.

5. Etz CD, Zoli S, Mueller CS, Bodian CA, Di Luozzo G, Lazala R, et al. Staged repair significantly reduces paraplegia rate after extensive thoracoabdominal aortic aneurysm repair. J Thorac Cardiovasc Surg. 2010;139:1464-72.

6. Dake MD, Miller DC, Mitchell RS, Semba CP, Moore KA, Sakai T. The "first generation" of endovascular stent-grafts for patients with aneurysms of the descending thoracic aorta. J Thorac Cardiovasc Surg. 1998;116:689-704.

7. Gravereaux EC, Faries PL, Burks JA, Latessa V, Spielvogel D, Hollier LH, et al. Risk of spinal cord ischemia after endograft repair of thoracic aortic aneurysms. J Vasc Surg. 2001;34:997-1003

8. Makaroun MS, Dillavou ED, Kee ST, Sicard G, Chaikof E, Bavaria J, et al. Endovascular treatment of thoracic aortic aneurysms: results of the phase II multicenter trial of the GORE TAG thoracic endoprosthesis. J Vasc Surg. 2005;41:1-9

9. Schlosser FJ, Verhagen HJ, Lin PH, Verhoeven EL, van Herwaarden JA, Moll FL, et al. TEVAR following prior abdominal aortic aneurysm surgery: increased risk of neurological deficit. J Vasc Surg. 2009;49:308-14.

10. Martin DJ, Martin TD, Hess PJ, Daniels MJ, Feezor RJ, Lee WA. Spinal cord ischemia after TEVAR in patients with abdominal aortic aneurysms. $J$ Vasc Surg. 2009;49:302-7

11. Hughes GC, Barfield ME, Shah AA, Williams JB, Kuchibhatla M, Hanna JM, et al. Staged total abdominal debranching and thoracic endovascular aortic repair for thoracoabdominal aneurysm. J Vasc Surg. 2012;56:621-9.

12. Bischoff MS, Scheumann J, Brenner RM, Ladage D, Bodian CA, Kleinman G, et al. Staged approach prevents spinal cord injury in hybrid surgicalendovascular thoracoabdominal aortic aneurysm repair: an experimental model. Ann Thorac Surg. 2011;92:138-46.

13. Etz CD, Di Luozzo G, Zoli S, Lazala R, Plestis KA, Bodian CA, et al. Direct spinal cord perfusion pressure monitoring in extensive distal aortic aneurysm repair. Ann Thorac Surg. 2009;87:1764-74

14. Griepp EB, Griepp RB. The collateral network concept: minimizing paraplegia secondary to thoracoabdominal aortic aneurysm resection. Texas Heart Inst J. 2010;37:672-4

15. Coselli JS, Poli de Figueiredo LF, LeMaire SA. Impact of previous thoracic aneurysm repair on thoracoabdominal aortic aneurysm management. Ann Thorac Surg. 1997;64:639-50.

16. Patel HJ, Upchurch GR Jr, Eliason JL, Criado E, Rectenwald J, Williams DM, et al. Hybrid debranching with endovascular repair for thoracoabdominal aneurysms: a comparison with open repair. Ann Thorac Surg. 2010;89:1475-81.

17. Wong DR, Parenti JL, Green SY, Chowdhary V, Liao JM, Zarda S, et al. Open repair of thoracoabdominal aortic aneurysm in the modern surgical era: contemporary outcomes in 509 patients. J Am Coll Surg. 2011;212:569-81.

18. Baril DT, Carroccio A, Ellozy SH, Palchik E, Addis MD, Jacobs TS, et al. Endovascular thoracic aortic repair and previous or concomitant abdominal aortic repair: is the increased risk of spinal cord ischemia real? Ann Vasc Surg. 2006;20:188-94.

19. Williams GM, Roseborough GS, Webb TH, Perler BA, Krosnick T. Preoperative selective intercostal angiography in patients undergoing thoracoabdominal aneurysm repair. J Vasc Surg. 2004;39:314-21.

\section{Discussion}

Dr Joseph S. Coselli (Houston, Tex). Thank you to the AATS for the opportunity to discuss the paper and for a terrific presentation.

Dr Griepp and the group at Mount Sinai have contributed enormously to our knowledge and understanding of spinal cord anatomy and pathophysiology over the years, and the group continues to make important observations in an effort to advance the field of thoracoabdominal repair, specifically regarding spinal cord protection and the prevention of the devastating complications of paraplegia.

With regards to your presentation, I have a couple of questions.

Animal models, although indispensable in our understanding of human pathology, have limitations. Spinal cord anatomy and its circulation, for example, differs greatly between pigs and humans. And your group has previously described these differences in great detail and have noted that the Yorkshire pigs, correcting for weight and body surface area, have much larger internal thoracic and subscapular arteries than the human, supplying extensive collateral blood flow to the lower body and consequently to the spinal cord. Pigs also have large bilateral vertebral arteries and smaller segmental, thoracic and lumbar arteries, and the aortic bifurcation is also quite different in the pig, with a median sacral artery arising as a large-caliber vessel approximating the size of the common iliac artery. Importantly, surgical ligation or coiling of the segmental arteries followed by delayed TEVAR is not a perfect replication of an open extensive thoracoabdominal aneurysm replacement and specifically the Crawford extent II repairs.

My question to you is, how would these differences go into the interpretation of your results? Further, how did the authors choose a 7- to 10-day time frame for the coil embolization? And how would the segmental arteries, which were coiled, which varied between the groups, how exactly were they chosen? And is there really an upper limit?

The other interesting thing would be that the reduction of histologic spinal cord damage was most prominent to the area in which segmental arteries were coiled. This implies a delicate balance of an ischemic stimulus leading to protective angiogenesis without immediate necrosis or permanent injury. How could you hypothesize about the specific protective factors that are activated by the limited hypoxia during coil embolization for segmental arteries? I agree with you entirely that the approach is novel and certainly worthy of a clinical trial.

Dr Geisbüsch. Thank you, Dr Coselli, for your comments and your questions. I would like to first comment on the 7- to 10-day time frame we chose. As you know, we previously undertook studies in our laboratory where we studied what happened after 2 -stage procedures. And for those procedures we chose a week in-between those staged repairs where we either surgically ligated the abdominal segmental arteries and the thoracic or through hybrid procedures, and we found that a week is enough, at least 
in pigs, to stimulate some kind of vascular remodeling and that this improved outcome dramatically.

Through anatomical studies we also studied the pathophysiology and we could see that after the operation there is a drop in collateral network pressure as a percentage of MAP, which we could measure, and then this pressure increases again 24 hours after the operation and recovers within 5 days. This is how we hypothesize that this is a vulnerable time frame during which vascular remodeling takes place.

During previous studies in the laboratory at Mount Sinai, in which we tried to image the vasculature of the spinal cord, we could see that the vessels nourishing the spinal cord-especially the anterior spinal artery-increases in diameter over a time frame of 5 days, and that is how we decided to try 7 to 10 days. In patients, obviously, we cannot be sure whether this is an adequate interval and that is why we think we need to identify a way to clinically monitor the induced ischemia and vascular remodeling to find the optimal interval after the induced ischemic stimulus for extensive aneurysm repair in patients.

We also observed that development of collaterals as response to diminished input after SA sacrifice is most prominent in the lower thoracic/upper lumbar region, whereas the vessels at the caudal and cranial ends of the spinal cord, chiefly the anterior spinal artery, increase in size as an immediate response. We therefore chose to embolize vessels in the T11 to L3 region to stimulate angiogenesis and arteriogenesis in advance. In contrast to 2-stage procedures, where a large number of intercostal vessels are sacrificed, we sought to find a less invasive strategy by occluding only a small number of SAs, and we succeeded in showing that this is enough to stimulate this protective arteriogenic/angiogenic response.

Dr Coselli. Your group has previously reported on improved results with paraplegia with staged repairs for thoracoabdominal aneurysms, but this particular model may be more akin to TEVAR in patients who have previously had abdominal aortic aneurysm replacement. 